\title{
Nonlinear Optical Properties of Halogenated Aniline Oligomers
}

\author{
Marconi B. S. Costa $^{1}$, Antonio C. Pavão ${ }^{1} \&$ Ana E. de A. Machado ${ }^{1}$ \\ ${ }^{1}$ Departamento de Química Fundamental, Universidade Federal de Pernambuco, Recife, Brazil \\ Correspondence: Antonio C. Pavão, Departamento de Química Fundamental, Universidade Federal de \\ Pernambuco, Recife, Av. Prof. Moraes Rego, 1235, Cidade Universitária 50670-901, Brazil. Tel: \\ 55-81-2126-7415. E-mail: pavao@ufpe.br
}

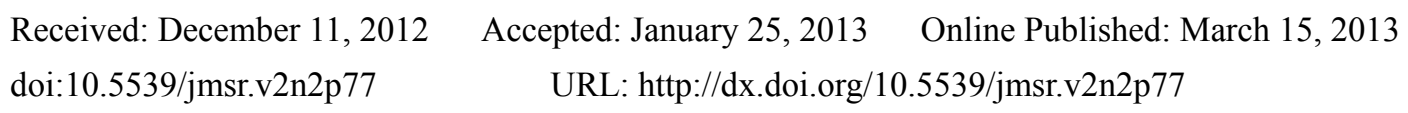

\begin{abstract}
High values of the first $(\beta)$ and second $(\gamma)$ hyperpolarizabilities were obtained for the halogenated oligomers of the three neutral forms of polyaniline (pernigraniline, emeraldine, and leucoemeraldine). For enhancement of the $\beta$ and $\gamma$ magnitudes, the t-butyl, t-butoxy, and dimethylamine electron donor groups were introduced into various halogenated oligomers. The effect of the oligomer chain size on the $\beta$ and $\gamma$ magnitude was also investigated by considering the aniline trimers and hexamers. The highest value of the dynamic $\beta$ hyperpolarizability $(1060 \mathrm{~nm})$ for the second-order harmonic generation (SHG) was found for a pernigraniline hexamer containing fluorine and dimethylamine substituents. The highest $\gamma$ hyperpolarizability magnitudes for the third-order harmonic generation (THG) were observed for all halogenated pernigraniline hexamers containing dimethylamine as a substituent. The AM1/TDHF results show that the halogenated aniline-based molecules are promising candidates for applications in nonlinear optics.
\end{abstract}

Keywords: halogenated aniline oligomers, nonlinear optical materials, AM1/TDHF calculations, hyperpolarizabilities

\section{Introduction}

Polyaniline shows exceptional optical, magnetic, chemical, and physical properties, as demonstrated in several experimental and theoretical works (Sajeev et al., 2010; Machado, 2001; Fitrilawati \& Tjia, 2001; Vivier, 2000; MacDiarmid, 1997; Geniès et al., 1990; Santos \& Brédas, 1989). This $\pi$-conjugated polymer lends itself to application in several areas, including energy storage, rectification and reversible conductance switching, optical biosensing, electrochromism, protection against corrosion, and use in transistors devices, among others (Chandrasoma et al., 2012; Fan et al., 2011; Nemzera \& Epsteina, 2010; Zhao et al., 2009; Bernard et al., 2001; Delongchamp \& Hammond, 2001; Bartllet et al., 2000; Vivier, 2000; Guo et al., 1999; Kim et al., 1999; Parente et al., 1992). Polyaniline exhibits enhanced values of the $(\gamma)$ optical second hyperpolarizability according to experimental measurements (Maciel et al., 1998; Halvorson et al., 1993; Cao et al., 1992; Osaheni et al., 1992). In addition, polyaniline and aniline derivatives present relevant magnitudes of the ( $\beta$ ) first hyperpolarizability, as has been experimentally and theoretically assessed (Costa et al., 2007; Machado \& da Gama, 2005; Machado et al., 2002; Azevêdo et al., 1998). AM1/TDHF calculations for the nonsubstituted and monosubstituted aniline oligomers containing an acceptor group attached at one end have shown a correlation between enhanced $\beta$ and $\gamma$ hyperpolarizabilities and an increase in the size of the oligomers (Costa et al., 2007; Machado \& da Gama, 2005; Machado et al., 2002).

The dimensionality of the system, molecular asymmetry, size and nature of the linker between the donor and acceptor groups, donor-acceptor (D-A) pair electronic strength, and molecular conformation are parameters that influence the $\beta$ and $\gamma$ magnitudes of the organic-based materials, as has been demonstrated by experimental and theoretical studies (Machado et al., 2008, 2011a; Champagne \& Kirtman, 2001; Kanis et al., 1994; Brédas et al., 1994). Recently, DFT calculation for aniline showed that larger hyperpolarizabilities in quintet state than the singlet state raises the possibility of spin multiplicity control of nonlinear responses (Deshmukh et al., 2012). Aromatic and mesoionic rings, as well as unsaturated chains, are the bridges usually used to synthesize new D-bridge-A compounds (Machado et al., 2008; Costa et al., 2007; Moura et al., 1996; Kanis et al., 1994). The organic molecule (or bulk medium) should be noncentrosymmetric in order to have a $\beta$ nonlinear response. For a $\gamma$ response there is no such restriction. In order to increase the magnitude of $\beta$ hyperpolarizability, a lowest energy 
electronic absorption is needed, as predicted by models based on perturbation theory (Kanis et al., 1994). In addition, nonlinear optical (NLO) materials should exhibit transparency and stability in the spectral range selected in order to be useful for practical applications.

In the present work, halogenated aniline derivatives are chosen to optimize the $\beta$ and $\gamma$ nonlinear coefficients. Previous results for stilbene derivatives show an increase in $\beta$ and $\gamma$ magnitudes when fluorine is attached to their structures (Romanielle \& Lelz, 2004; Kanis et al., 1994). Also, iodine-substituted derivatives of (2-methylnaphthyl)imido]hexamolybdate exhibit large first hyperpolarizabilities (Yan et al., 2008). Some halogenated oligomers of the aniline neutral forms, such as leucoemeraldine, emeraldine and pernigraniline (Figure 1), were chosen for investigation. Fully and semi-oxidized structures are found in pernigraniline and emeraldine, respectively, whereas leucoemeraldine has a fully reduced structure. The aniline derivatives studied contain fluorine, chlorine, bromine and iodine substituents. The effect of chain size on the magnitude of the hyperpolarizabilities was addressed by considering the halogenated trimers and hexamers of the aniline. In addition, some halogenated hexamers containing a donor substituent linked at one terminal aromatic ring of the oligomers were studied in order to improve the $\beta$ and $\gamma$ nonlinear responses. The t-butyl $\left[-\mathrm{C}\left(\mathrm{CH}_{3}\right)_{3}\right]$, t-butoxy $\left[-\mathrm{OC}\left(\mathrm{CH}_{3}\right)_{3}\right]$ and dimethylamine $\left[-\mathrm{N}\left(\mathrm{CH}_{3}\right)_{2}\right]$ donor groups were selected in this investigation. These groups contribute to the relevant $\beta$ and $\gamma$ values of the aniline octamers containing the dicyanoethenyl acceptor group for the leucoemeraldine and emeraldine forms according to theoretical studies (Costa et al., 2007; Blanchard-Desce et al., 1997a, 1997b; Vaschetto \& Retamal, 1997). It should be emphasized that aniline oligomers have not only a solubility in common laboratorial solvents, which is not observed in polyaniline itself, but also a crystallization (Sein et al., 2000a, 2000b; Jansen et al., 1999; Sein et al., 1999; Boudreaux et al., 1986), properties required if the aniline oligomers are to be used in the manufacturing of devices.

The $\beta$ and $\gamma$ hyperpolarizabilities of the aniline derivatives for the second- (SHG) and third- (THG) harmonic generation were calculated using the AM1/TDHF methodology (Karna \& Dupuis, 1991; Dewar et al., 1985), as implemented in the MOPAC2009 computational code (MOPAC2009). Early theoretical results utilizing the same methodology for the $\gamma$ hyperpolarizability of model trimers of polyaniline neutral forms are in agreement with the experimental trends observed for the polymer (Machado et al., 2002). For the $\beta$ hyperpolarizability, the least value is assigned to the leucoemeraldine, while the higher values are due to the pernigraniline and emeraldine forms. The AM1/TDHF (and PM3) method allowed for successful calculation of the $\beta$ hyperpolarizability of organic molecules (Romanielle \& Lelz, 2004; Moura et al., 1996). Moreover, several nonsubstituted and substituted oligomers of aniline having the dicyanoethenyl acceptor group at the end of their structures show significant $\beta$ and $\gamma$ values according to the AM1/TDHF calculations (Costa et al., 2007; Machado et al., 2002, 2005). The results obtained demonstrate that the aniline oligomeric systems investigated are promising as second- and third-order nonlinear optical materials. In particular, the pernigraniline hexamer containing the fluorine and dimethylamine substituents show the highest $\beta$ and $\gamma$ values among all oligomers functionalized.<smiles>Nc1ccc(Nc2ccc(Nc3ccc(F)cc3)cc2)cc1</smiles><smiles>Nc1ccc(N=C2C=CC(=Nc3ccc(S)cc3)C=C2)cc1</smiles><smiles>N=C1C=CC(=Nc2ccc(N=C3C=CC(=NS)C=C3)cc2)C=C1</smiles>

Figure 1. Aniline trimers investigated: (a) leucoemeraldine, (b) emeraldine and (c) pernigraniline, where the (F, $\mathrm{Cl}$, $\mathrm{Br}, \mathrm{I})$ substituent is quoted as $S$ 


\section{Methodology}

The geometries of all aniline oligomers studied were fully optimized with the Austin Model 1 (AM1) Hamiltonian using the MOPAC2009 computational code (MOPAC2009; Dewar et al., 1985). The values of the dynamic hyperpolarizabilities $\beta$ and $\gamma$ for the second (SHG) and third (THG) harmonic generation, respectively, were calculated with the Time Dependent Hartree-Fock (TDHF) methodology, as implemented in MOPAC2009 (Stewart, 1996; Karna \& Dupuis, 1991; Dewar et al., 1985). The AM1/TDHF methodology satisfactorily reproduces the experimental trend of $\beta$ and $\gamma$ hyperpolarizabilities of D-A organic molecules (Machado \& da Gama, 2003; Machado et al., 2002; Machado, 2001; Moura et al., 1996); it also reproduces the experimental trend of $\beta$ using MP2 and DFT (Machado et al., 2011b). Applied in a large system, this method is advantageous because it is very fast compared to $a b$ initio methods. The TDHF method accounts for the interaction of the electrons of closed shell systems with the external electrical field. A dipolar interaction Hamiltonian relative to the perturbation is introduced in the electronic part of the time-dependent Shrödinger equation. The polarization $(\vec{P})$ of a molecule under an external electromagnetic field is described in terms of an $n$ order electric susceptibility tensor. The first order term is denoted as the $\alpha$ polarizability, the second order term is the first hyperpolarizability $(\beta)$, and the third order term is the second hyperpolarizability $(\gamma)$. The polarization can be written in a power series of the electric field:

$$
\vec{P}=\chi^{(1)} \vec{F}+\chi^{(2)} \vec{F} \vec{F}+\chi^{(3)} \vec{F} \vec{F} \vec{F}+\ldots
$$

where $\chi^{n}$ is the susceptibility tensor of order $n$, and the electromagnetic field $\vec{F}$ is the matrix with the components of intensity in the $x, y$, and $z$ directions.

For a molecule, this equation takes the form:

$$
\vec{p}=\sum_{j} \alpha_{i j} \vec{F}_{j}+\sum_{j \leq k} \beta_{i j k} \vec{F}_{j} \vec{F}_{k}+\sum_{j \leq k \leq l} \gamma_{i j k l} \vec{F}_{j} \vec{F}_{k} \vec{F}_{l}+\ldots
$$

where $\alpha_{i j}, \beta_{i j k}, \gamma_{i j k l}$, are of the first, second, and third order tensors, respectively. The subscript terms $i, j, k$, and $l$ refer to the directions $x, y$, and $z$.

The hyperpolarizabilities are computed using equations $\beta_{\mathrm{abc}}=-\operatorname{Tr}\left[H^{\mathrm{a}} D^{\mathrm{bc}}\right]$ and $\gamma_{\mathrm{abcd}}=-\operatorname{Tr}\left[H^{\mathrm{a}} D^{\mathrm{bcd}}\right]$, where $H$ and $D$ are the dipole moment and the density matrix, respectively. $\operatorname{Tr}$ is the matrix trace, and the indices $a, b, c$, and $d$ refer to the directions $x, y$, and $z$. Moreover, the static values $\beta$ and $\gamma$ were also calculated through the Coupled-Perturbed Time Dependent (CPHF) method (Dykstra \& Jasien, 1984).

The twenty-four derivatives (trimers and hexamers) of three aniline forms namely leucoemeraldine, emeraldine, and pernigraniline, were designed containing the fluorine, chlorine, bromine, and iodine substituents. First, the halogen atom was introduced in the terminal aromatic ring of the leucoemeraldine and emeraldine trimer structure (Figure 1). For the pernigraniline, the halogen atom was attached at the nitrogen atom of the imine group (Figure 1). In the case of hexamers, the substituents are bound to the aromatic ring for all aniline forms. In addition, some hexamers containing a donor group linked at one terminal aromatic ring that has the halogen atom were modeled. The t-butyl $\left[-\mathrm{C}\left(\mathrm{CH}_{3}\right)_{3}\right]$, t-butoxy $\left[-\mathrm{OC}\left(\mathrm{CH}_{3}\right)_{3}\right]$, and dimethylamine $\left[-\mathrm{N}\left(\mathrm{CH}_{3}\right)_{2}\right]$ donor groups were selected in the present work. The results for halogenated hexamers were compared to those obtained for the nonsubstituted hexamers. The ionization potential (IP), the ground state dipole moment $(\mu)$, and the HOMO-LUMO energy gap $\left(\Delta_{\mathrm{H}-\mathrm{L}}\right)$ were also obtained using the AM1 method.

\section{Results and Discussion}

The AM1/TDHF values of the static and dynamic $\beta$ and $\gamma$ hyperpolarizabilities of the halogenated aniline trimers and hexamers (Figure 1) are shown in Tables 1-2. The dynamic $\beta$ and $\gamma$ (SHG and THG) values were calculated at $1060 \mathrm{~nm}$ and $2479 \mathrm{~nm}$, respectively. The values of the ground state dipole moment $(\mu)$, the HOMO-LUMO energy gap $\left(\Delta_{\mathrm{H}-\mathrm{L}}\right)$, and the ionization potential (IP) are also reported.

All of the halogenated emeraldine trimers show the highest values of the static and dynamic $\beta$ hyperpolarizability among the halogenated aniline trimers and hexamers investigated (Tables 1-2). These trimers also present the smallest values of the $\Delta_{\mathrm{H}-\mathrm{L}}$ (Figure 3b) and show higher $\mu$ values. The dynamic $\beta$ values for the designed oligomers of pernigraniline are also significant; for leucoemeraldine, however, only the hexamers show high values of this nonlinear coefficient. The fluorinated emeraldine trimer presents the best performance relative for $\beta$ among all halogenated trimers and hexamers studied (Figures 2 and 3). This finding shows that the redox state of the polyaniline is crucial to obtaining new second-order materials. The emeraldine state has the least HOMO-LUMO energy gap among the halogenated aniline oligomers, according to the AM1/TDHF calculations (Figure 3). These 
hexamers show very small values of the $\mu$ and large values of the ionization potential, where the latter favors practical applications.

Table 1. Calculated properties of aniline halogenated trimers

\begin{tabular}{|c|c|c|c|c|c|c|c|c|}
\hline Structure & System & $\begin{array}{c}\beta_{0} \\
\left(10^{-30} \mathrm{esu}\right)\end{array}$ & $\begin{array}{c}\beta_{1060} \\
\left(10^{-30} \mathrm{esu}\right)\end{array}$ & $\begin{array}{c}\gamma_{0} \\
\left(10^{-36} \mathrm{esu}\right)\end{array}$ & $\begin{array}{c}\gamma_{2479} \\
\left(10^{-36} \mathrm{esu}\right)\end{array}$ & $\begin{array}{l}\mu \\
(D)\end{array}$ & $\begin{array}{l}\Delta_{\mathrm{H}-\mathrm{L}} \\
(\mathrm{eV})\end{array}$ & $\begin{array}{c}\text { IP } \\
(\mathrm{eV})\end{array}$ \\
\hline & $L F$ & 10 & 23 & 63 & 86 & 4.28 & 7.88 & 7.91 \\
\hline & $L C l$ & 10 & 23 & 67 & 91 & 4.18 & 7.90 & 7.94 \\
\hline & $L B r$ & 12 & 26 & 70 & 96 & 4.45 & 7.95 & 7.96 \\
\hline & $L I$ & 12 & 28 & 71 & 98 & 4.52 & 7.95 & 7.97 \\
\hline & $E F$ & 42 & 250 & 330 & 546 & 5.63 & 6.60 & 8.13 \\
\hline & $\mathrm{ECl}$ & 40 & 234 & 342 & 563 & 5.21 & 6.61 & 8.13 \\
\hline & $E B r$ & 40 & 240 & 350 & 580 & 5.36 & 6.60 & 8.13 \\
\hline & $E I$ & 40 & 248 & 357 & 592 & 5.32 & 6.60 & 8.12 \\
\hline & $P F$ & 10 & 70 & 481 & 784 & 2.11 & 6.63 & 8.61 \\
\hline & $P C l$ & 10 & 74 & 507 & 830 & 2.06 & 6.64 & 8.62 \\
\hline & $P B r$ & 11 & 83 & 521 & 854 & 2.05 & 6.65 & 8.63 \\
\hline & $P I$ & 12 & 87 & 523 & 857 & 1.88 & 6.66 & 8.63 \\
\hline
\end{tabular}

$L, E$, and $P$ are the leucoemeraldine, emeraldine, and pernigraniline forms respectively, $\beta_{0}\left(\gamma_{0}\right)$ is the static value, $\beta_{1060}\left(\gamma_{2479}\right)$ is the dynamic value at the $1060 \mathrm{~nm}(2479 \mathrm{~nm}), \mu$ is the ground state dipole moment, $\Delta_{\mathrm{H}-\mathrm{L}}$ is the HOMO-LUMO energy gap and the IP is the ionization potential.

Table 2. Calculated properties of aniline halogenated hexamers $(n=2)$

\begin{tabular}{|c|c|c|c|c|c|c|c|c|}
\hline Structure & System & $\begin{array}{c}\beta_{0} \\
\left(10^{-30} \mathrm{esu}\right)\end{array}$ & $\begin{array}{c}\beta_{1060} \\
\left(10^{-30} \mathrm{esu}\right)\end{array}$ & $\begin{array}{c}\gamma_{0} \\
\left(10^{-36} \mathrm{esu}\right)\end{array}$ & $\begin{array}{c}\gamma_{2479} \\
\left(10^{-36} \mathrm{esu}\right)\end{array}$ & $\begin{array}{c}\mu \\
(\mathrm{D})\end{array}$ & $\begin{array}{l}\Delta_{\mathrm{H}-\mathrm{L}} \\
(\mathrm{eV})\end{array}$ & $\begin{array}{r}\text { IP } \\
(\mathrm{eV})\end{array}$ \\
\hline & $L$ & 25 & 66 & 239 & 344 & 4.56 & 7.68 & 7.72 \\
\hline & $L F$ & 27 & 74 & 238 & 343 & 6.76 & 7.69 & 7.75 \\
\hline & $L C l$ & 27 & 71 & 240 & 344 & 6.77 & 7.72 & 7.77 \\
\hline & $L B r$ & 28 & 75 & 244 & 350 & 7.05 & 7.71 & 7.78 \\
\hline & $L I$ & 29 & 76 & 245 & 353 & 7.11 & 7.71 & 7.77 \\
\hline & $E$ & 15 & 98 & 779 & 1321 & 2.63 & 6.72 & 8.08 \\
\hline & $E F$ & 11 & 60 & 900 & 1554 & 2.63 & 6.66 & 8.10 \\
\hline & $E C l$ & 13 & 67 & 909 & 1564 & 2.67 & 6.66 & 8.11 \\
\hline & $E B r$ & 12 & 66 & 914 & 1573 & 2.84 & 6.66 & 8.11 \\
\hline & $E I$ & 11 & 61 & 883 & 1507 & 2.89 & 6.68 & 8.13 \\
\hline & $P$ & 7 & 31 & 903 & 1509 & 2.93 & 6.92 & 8.56 \\
\hline & $P F$ & 10 & 64 & 900 & 1502 & 1.47 & 6.92 & 8.62 \\
\hline & 10 & 9 & 59 & 924 & 1544 & 1.73 & 6.92 & 8.61 \\
\hline & $\mathrm{PBr}$ & 12 & 79 & 965 & 1619 & 1.87 & 6.91 & 8.61 \\
\hline & $P I$ & 11 & 75 & 952 & 1590 & 1.87 & 6.92 & 8.62 \\
\hline
\end{tabular}

$L, E$, and $P$ are the leucoemeraldine, emeraldine and pernigraniline forms respectively, $\beta_{0}\left(\gamma_{0}\right)$ is the static value, $\beta_{1060}\left(\gamma_{2479}\right)$ is the dynamic value at the $1060 \mathrm{~nm}(2479 \mathrm{~nm}), \mu$ is the ground state dipole moment, $\Delta_{\mathrm{H}-\mathrm{L}}$ is the HOMO-LUMO energy gap, and the IP is the ionization potential. 


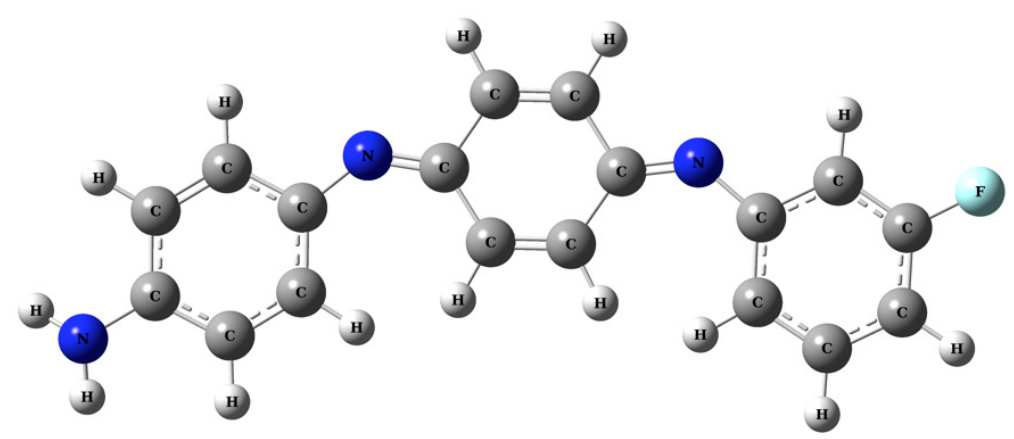

Figure 2. Optimized geometry of fluorinated emeraldine trimer

It was found that the halogenated hexamers of aniline present high values of $\beta$, in agreement with previous studies (Costa et al., 2007, 2012; Machado et al., 2004; Machado et al., 2011a). For leucoemeraldine hexamers the higher values of $\beta$ are associated with the smaller values of $\Delta_{\mathrm{H}-\mathrm{L}}$ (Figure 3a). The emeraldine trimers show the highest $\beta$ values, as well as the smallest $\Delta_{\mathrm{H}-\mathrm{L}}$ gap (Figure $3 \mathrm{~b}$ ). The optimized geometries for the emeraldine and pernigraniline trimers are planar, while for the hexamers they are not planar. Hence, the resonance contributes to the highest values observed in emeraldine and pernigraniline trimers but not for trimers and hexamers of leucoemeraldine, which are not planar.

The contribution of the dipole moment explains the smaller values of $\beta$ observed for the pernigraniline trimers, since these systems present smaller values of $\mu$ compared to those observed for emeraldine trimers. In addition, the halogen substituent is bound to the imine nitrogen of the quinoid ring, while for the hexamers of the same form, the substituent is attached directly to the aromatic ring, which is also the case for the leucoemeraldine and emeraldine derivatives. These electronic and structural differences result in distinct behaviors observed in the nonlinear optical properties. Moreover, according to the perturbation theory, the $\beta$ magnitude depends inversely on the energy gap and directly on a difference between ground state and excited dipole moment (Champagne \& Kirtman, 2001; Kanis et al., 1994). The photophysical properties of the analyzed systems depend on the selected halogen, as can be inferred from the large range of the ground state dipole moment and HOMO-LUMO energy gap values (Tables 1-2). 


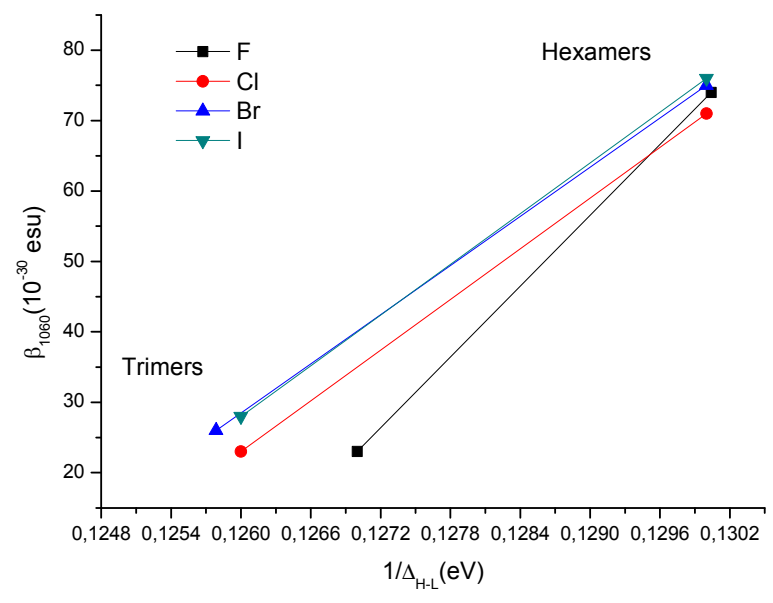

(a)

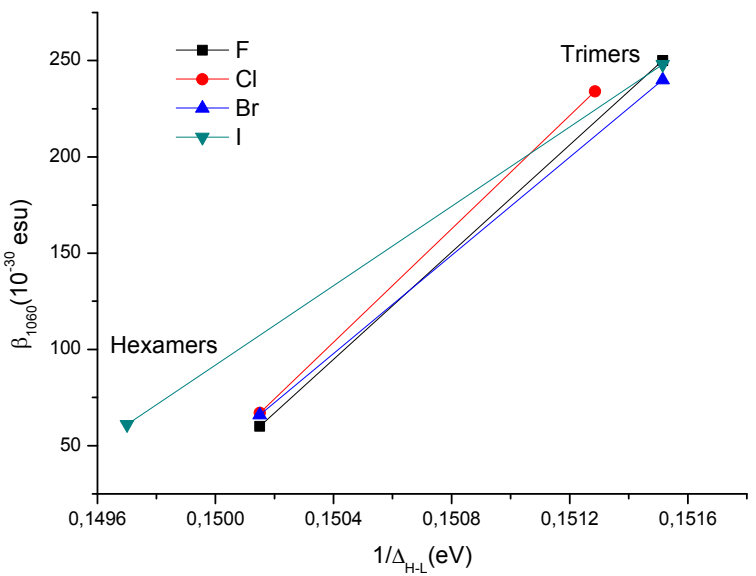

(b)

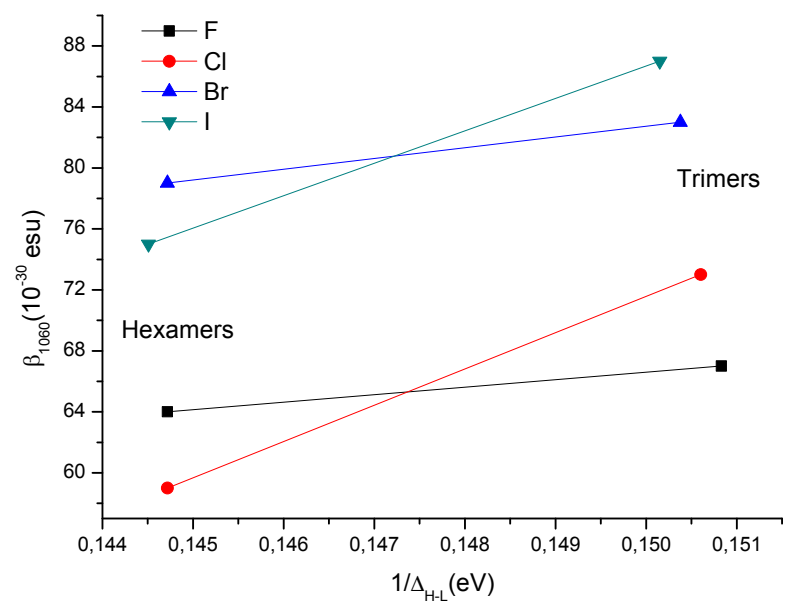

(c)

Figure 3. Dynamic $\beta(1060 \mathrm{~nm})$ with the inverse of HOMO-LUMO energy gap $\left(1 / \Delta_{\mathrm{H}-\mathrm{L}}\right)$ for halogenated derivatives of leucoemeraldine (a), emeraldine (b) and pernigraniline (c)

The $\gamma$ magnitudes for the halogenated oligomers of the emeraldine and pernigraniline studied are very large and have the same order magnitude for each halogen considered (Figure 4). It can be concluded that the redox state of the polyaniline is crucial to the development of new third-order materials. It should be noted that increasing the chain size results in the enhancement of the $\gamma$ magnitude for all forms of aniline (Table 2). However, enlarging the chain size of emeraldine results in a marked decrease of the $\beta$ values because of the torsions between the chain rings in this state of polyaniline, as already observed in experiments and in theoretical studies for short chain sizes of oligophenylenes and oligothiophenes (Libert et al., 1997; Cheng et al., 1991; Ledoux et al., 1991; Morley et al., 1987). The highest $\gamma$ values obtained are of the same magnitude order as carotenoid, which is an important third-order material according to experimental and theoretical assessment (Machado \& da Gama, 2008; Marder et al., 1997; Brédas et al., 1994). Therefore, the synthesis of the derivatives investigated in the present work will assist experimental chemists in selecting materials with optimal performance for use in practical applications. The fundamental properties required for practical applications are transparency, high thermal and environmental stability, high threshold optical damage, and ultra-fast nonlinear responses (Sajeev et al., 2010; Champagne \& Kirtman, 2001; Kanis et al., 1994; Brédas et al., 1994). The redox state fully reduced shows that the highest $\gamma$ values are associated with the smallest $\Delta_{\mathrm{H}-\mathrm{L}}$ values (Figure 4a), while for the semi-oxidized (Figure 4b) and fully oxidized (Figure 4c) redox state, a behavior contrary to that observed for the leucoemeraldine form is produced. 


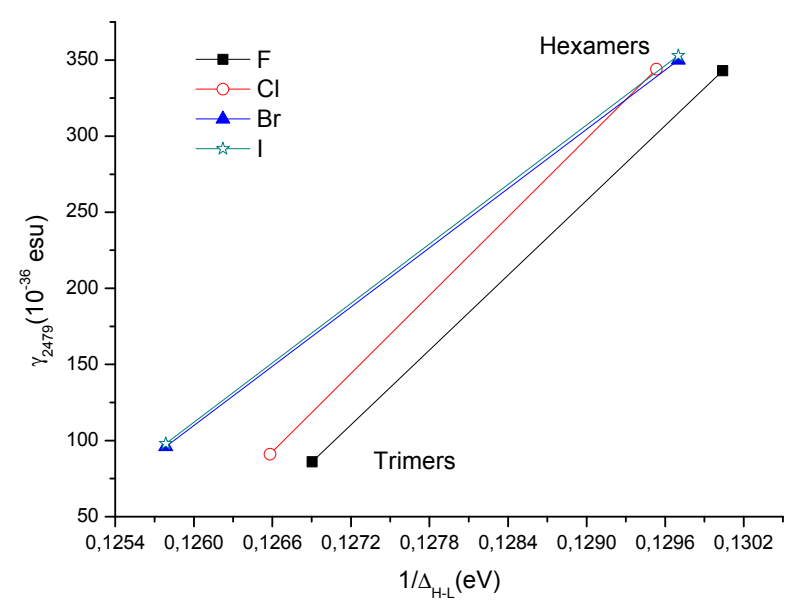

(a)

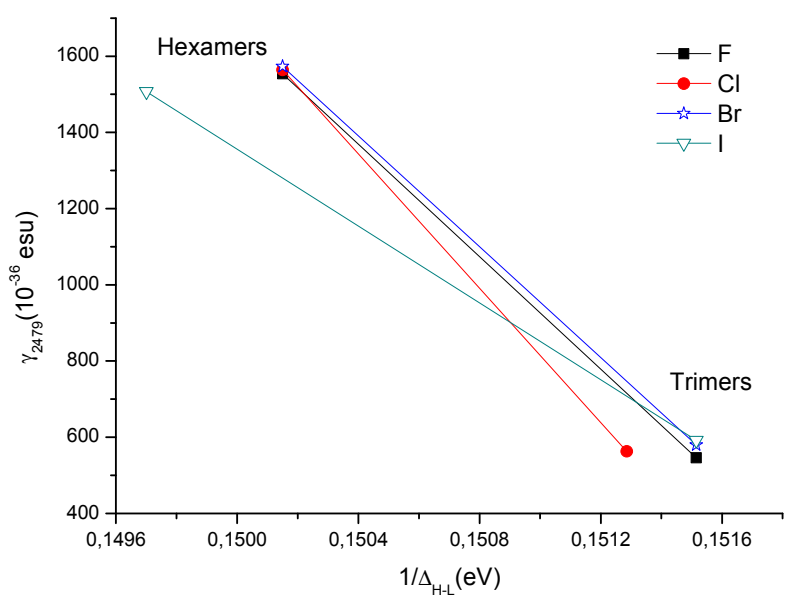

(b)

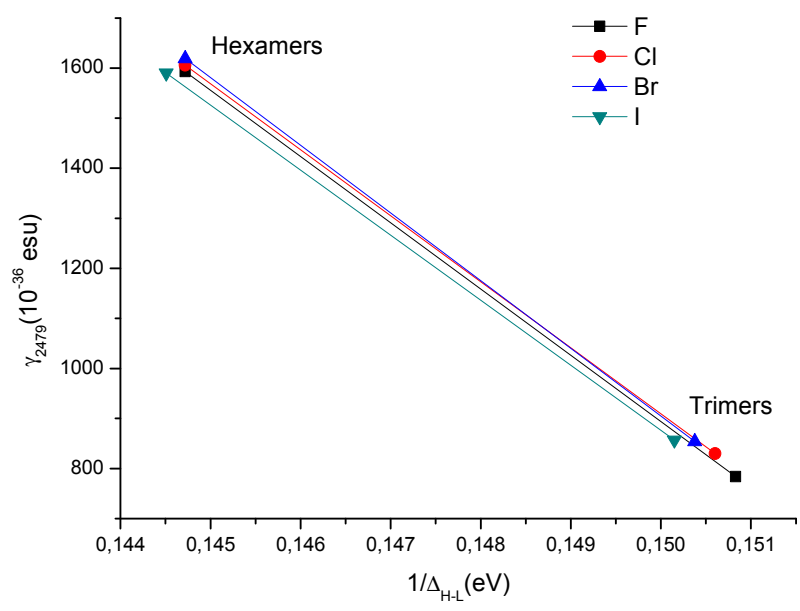

(c)

Figure 4. Dynamic $\gamma(2479 \mathrm{~nm})$ with the inverse of HOMO-LUMO energy gap $\left(1 / \Delta_{\mathrm{H}-\mathrm{L}}\right)$ of halogenated derivatives of leucoemeraldine (a), emeraldine (b), and pernigraniline (c)

Subsequently, a donor (D) group was introduced at the terminal aromatic ring of the halogenated hexamers (Figure 5). The donor groups chosen were t-butyl $\left[-\mathrm{C}\left(\mathrm{CH}_{3}\right)_{3}\right]$, t-butoxy $\left[-\mathrm{OC}\left(\mathrm{CH}_{3}\right)_{3}\right]$, and dimethylamine $\left[-\mathrm{N}\left(\mathrm{CH}_{3}\right)_{2}\right]$. These groups contribute to the enhanced hyperpolarizabilities found for other classes of nonlinear materials theoretically and experimentally investigated (Brennand \& Machado, 2010; Costa et al., 2007; Blanchard-Desce et al., 1997a, 1997b; Vaschetto \& Retamal, 1997). The results of the $\gamma$ hyperpolarizability obtained for the halogenated hexamers having a donor group are promising for the emeraldine and pernigraniline forms (Table 3 ). For the $\beta$ hyperpolarizability of three neutral forms of polyaniline, relevant values for all derivatives containing a donor group are observed, as noted in Table 3 . 
Table 3. Calculated properties of aniline halogenated hexamers containing a donor group

\begin{tabular}{|c|c|c|c|c|c|c|c|}
\hline System & $\begin{array}{c}\beta_{0} \\
\left(10^{-30} \text { esu }\right) \\
\end{array}$ & $\begin{array}{c}\beta_{1060} \\
\left(\mathbf{1 0}^{-30} \text { esu }\right) \\
\end{array}$ & $\begin{array}{c}\gamma_{0} \\
\left(10^{-36} \text { esu }\right) \\
\end{array}$ & $\begin{array}{c}\gamma_{2479} \\
\left(10^{-36} \mathrm{esu}\right) \\
\end{array}$ & $\begin{array}{c}\mu \\
\text { (D) }\end{array}$ & $\begin{array}{l}\Delta_{\mathrm{H}-\mathrm{L}} \\
(\mathrm{eV})\end{array}$ & $\begin{array}{c}\text { IP } \\
(\mathrm{eV})\end{array}$ \\
\hline \multicolumn{8}{|c|}{ Leucoemeraldine } \\
\hline$F L-D_{1}$ & 26 & 67 & 240 & 343 & 6.39 & 7.73 & 7.77 \\
\hline$C I L-D_{1}$ & 25 & 68 & 250 & 358 & 6.07 & 7.69 & 7.75 \\
\hline$B r L-D_{1}$ & 27 & 73 & 252 & 362 & 6.39 & 7.69 & 7.76 \\
\hline$I L-D_{1}$ & 27 & 74 & 255 & 367 & 6.26 & 7.68 & 7.75 \\
\hline$F L-D_{2}$ & 25 & 66 & 248 & 355 & 7.46 & 7.72 & 7.76 \\
\hline$C l L-D_{2}$ & 24 & 66 & 252 & 362 & 7.02 & 7.69 & 7.76 \\
\hline$B r L-D_{2}$ & 25 & 69 & 255 & 366 & 7.47 & 7.68 & 7.75 \\
\hline$I L-D_{2}$ & 26 & 71 & 256 & 368 & 7.37 & 7.69 & 7.76 \\
\hline$F L-D_{3}$ & 23 & 59 & 247 & 354 & 5.79 & 7.71 & 7.74 \\
\hline$C l L D_{3}$ & 24 & 72 & 236 & 345 & 6.66 & 7.72 & 7.94 \\
\hline $\mathrm{BrLD}_{3}$ & 25 & 65 & 261 & 375 & 6.45 & 7.68 & 7.74 \\
\hline$I L D_{3}$ & 27 & 30 & 73 & 256 & 368 & 7.30 & 7.65 \\
\hline \multicolumn{8}{|l|}{ Emeraldine } \\
\hline$F E D_{1}$ & 13 & 66 & 908 & 1561 & 2.68 & 6.67 & 8.09 \\
\hline$C l E D_{1}$ & 12 & 63 & 881 & 1501 & 1.80 & 6.69 & 8.11 \\
\hline$B r E D_{1}$ & 11 & 63 & 884 & 1507 & 1.76 & 6.69 & 8.11 \\
\hline$I E D_{1}$ & 11 & 62 & 900 & 1539 & 1.75 & 6.68 & 8.11 \\
\hline$F E D_{2}$ & 14 & 88 & 840 & 1425 & 3.97 & 6.67 & 8.14 \\
\hline $\mathrm{ClED}_{2}$ & 16 & 77 & 873 & 1487 & 2.05 & 6.68 & 8.08 \\
\hline $\mathrm{BrED}_{2}$ & 14 & 84 & 785 & 1358 & 1.63 & 6.78 & 8.15 \\
\hline$I E D_{2}$ & 16 & 78 & 882 & 1502 & 2.08 & 6.69 & 8.09 \\
\hline $\mathrm{FED}_{3}$ & 15 & 74 & 904 & 1548 & 3.74 & 6.64 & 8.04 \\
\hline $\mathrm{ClED}_{3}$ & 13 & 68 & 891 & 1521 & 2.62 & 6.66 & 8.10 \\
\hline $\mathrm{BrED}_{3}$ & 13 & 69 & 908 & 1552 & 2.72 & 6.66 & 8.10 \\
\hline$I E D_{3}$ & 11 & 59 & 843 & 1427 & 2.44 & 6.71 & 8.13 \\
\hline \multicolumn{8}{|c|}{ Pernigraniline } \\
\hline$F P D_{1}$ & 13 & 87 & 973 & 1620 & 1.97 & 6.93 & 8.61 \\
\hline$C l P D_{1}$ & 20 & 97 & 939 & 1556 & 0.99 & 6.97 & 8.60 \\
\hline$B r P D_{1}$ & 20 & 96 & 933 & 1543 & 1.12 & 6.9 & 8.61 \\
\hline$I P D_{1}$ & 20 & 97 & 961 & 1597 & 1.11 & 6.97 & 8.60 \\
\hline $\mathrm{FPD}_{2}$ & 13 & 54 & 1043 & 1751 & 2.89 & 6.88 & 8.53 \\
\hline$C l P D_{2}$ & 22 & 102 & 948 & 1578 & 2.35 & 6.96 & 8.59 \\
\hline $\mathrm{BrPD}_{2}$ & 9 & 38 & 1030 & 1725 & 2.41 & 6.93 & 8.58 \\
\hline$I P D_{2}$ & 5 & 13 & 1043 & 1747 & 2.44 & 6.93 & 8.58 \\
\hline $\mathrm{FPD}_{3}$ & 52 & 350 & 1098 & 1877 & 2.42 & 6.62 & 8.20 \\
\hline $\mathrm{ClPD}_{3}$ & 19 & 100 & 1118 & 1895 & 1.98 & 6.87 & 8.52 \\
\hline $\mathrm{BrPD}_{3}$ & 15 & 71 & 1082 & 1826 & 2.08 & 6.90 & 8.55 \\
\hline$I P D_{3}$ & 7 & 8 & 1117 & 1896 & 2.24 & 6.88 & 8.56 \\
\hline
\end{tabular}

$L, E$, and $P$ are the leucoemeraldine, emeraldine and pernigraniline forms, respectively, $\beta_{0}\left(\gamma_{0}\right)$ is the static value, $\beta_{1060}\left(\gamma_{2479}\right)$ is the dynamic value at the $1060 \mathrm{~nm}(2479 \mathrm{~nm}), \mu$ is the ground state dipole moment, $\Delta_{\mathrm{H}-\mathrm{L}}$ is the HOMO-LUMO energy gap and the IP is the ionization potential. $\mathrm{D}_{1}, \mathrm{D}_{2}$, and $\mathrm{D}_{3}$ represent the t-butyl $\left[-\mathrm{C}\left(\mathrm{CH}_{3}\right)_{3}\right]$, t-butoxy $\left[-\mathrm{OC}\left(\mathrm{CH}_{3}\right)_{3}\right]$ and dimethylamine $\left[-\mathrm{N}\left(\mathrm{CH}_{3}\right)_{2}\right]$ donor group, respectively. 
<smiles>Nc1ccc(Nc2ccc(Nc3ccc(Nc4ccc(Nc5ccc(Nc6ccc(F)c(Br)c6)cc5)cc4)cc3)cc2)cc1</smiles><smiles>Nc1ccc(N=C2C=CC(=Nc3ccc(Nc4ccc(N=C5C=CC(=Nc6ccc(F)c(Br)c6)C=C5)cc4)cc3)C=C2)cc1</smiles><smiles>N=C1C=CC(=Nc2ccc(N=C3C=CC(=Nc4ccc(N=C5C=CC(=Nc6ccc(Br)c(Br)c6)C=C5)cc4)C=C3)cc2)C=C1</smiles>

Figure 5. Aniline hexamers: (a) leucoemeraldine, (b) emeraldine and (c) pernigraniline, where $\mathrm{S}=\mathrm{F}, \mathrm{Cl}, \mathrm{Br}$, I and $\mathrm{D}$ is the donor group

The halogenated pernigraniline hexamers having dimethylamine group show the highest magnitudes $\gamma$ observed (Table 3) among all the systems investigated. The full geometry optimized for the system with the highest magnitudes $\gamma$ is shown in the Figure 6. Hence, the introduction of the dimethylamine group contributes strongly to the increase in the $\gamma$ nonlinear response. As the calculations were performed at the $2479 \mathrm{~nm}$ frequency, we expected a considerable increase at higher frequencies due the dispersive effect. Also, the fluorinated pernigraniline hexamer substituted with the dimethylamine group exhibits the largest $\beta$ value among the systems designed (Figure 7). This value is of the same magnitude order as the value experimentally observed for polyaniline (Azevêdo et al., 2002). These systems with highest values of $\beta$ and $\gamma$ present very small $\Delta_{\mathrm{H}-\mathrm{L}}$ values as observed for other nonlinear organic molecules (Costa et al., 2007, 2012; Machado et al., 2004, 2011a).

For the leucoemeraldine hexamers containing the donor group, their nonlinear coefficient has the same magnitude order as noted for the emeraldine ones (Tables 3). The corresponding experimental values are higher than the AM1/TDHF values, since a minimal basis is utilized and the electronic correlation, the vibrational and solvent effect are not incorporated in this semiempirical approach (Machado \& da Gama, 2003; Champagne et al., 2001). The potential ionization of all oligomers designed is large, which is indicative of the high stability of this class of nonlinear optical material (Geniès et al., 1990).

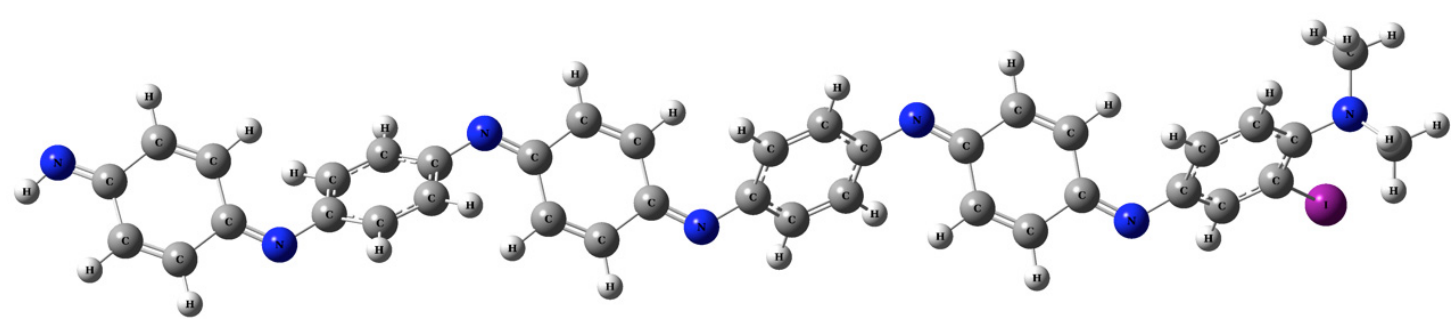

Figure 6. The pernigraniline hexamer containing the iodine and dimethylamine substitutents with the highest value of $\gamma$

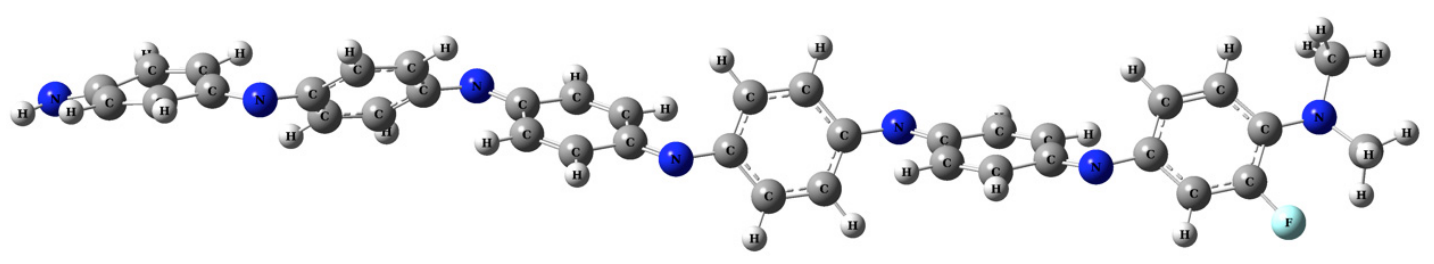

Figure 7. The pernigraniline hexamer containing the fluorine and dimethylamine substitutents with the highest value of $\beta$

Experimental measurements of $\beta$ values for the polyaniline monomeric residue, as determined by hyper-Rayleigh 
scaterring (HRS) at $1060 \mathrm{~nm}$, show that the pernigraniline form displays the best performance, whereas the leucoemeraldine form has a smaller value (Azevêdo et al., 2002). As shown in Table 3, the hexamer of the pernigraniline containing fluorine and dimethylamine displays the highest $\beta$ value. In relation to $\gamma$, emeraldine presents the best perfomance; pernigraniline has an intermediary value, and leucoemeraldine exhibits the smallest magnitude (Maciel et al., 1998; Halvorson et al., 1993; Osaheni et al., 1992). The results indicate that our selected substitution pattern effectively increases the $\gamma$ values of the pernigraniline and emeraldine oligomers, in agreement with experiments.

\section{Conclusions}

The very large $\gamma$ values obtained using the AM1/TDHF method for the pernigraline and emeraldine hexamers demonstrate promising practical applications. Increasing the oligomers chain size can contribute to enhancement of the magnitudes of the $\gamma$ nonlinear response. Also, the modeling performed demonstrates the potential use as nonlinear media of the substituted aniline oligomeric systems due to the enhanced values of $\beta$ obtained for the halogenated emeraldine trimers, as well as for the fluorinated pernigraniline hexamer substituted with dimethylamine. There are no $\beta$ and $\gamma$ experimental or theoretical data for these aniline oligomers; our results are the first predictions for these systems. These findings give a good direction to synthesize new aniline-based derivatives as second- and third-order nonlinear optical materials. In addition, more efficient donor groups and other substitution patterns to optimize the $\beta$ and $\gamma$ hyperpolarizabilities should be further investigated.

\section{Acknowledgements}

We gratefully acknowledge the financial support of the Conselho Nacional de Desenvolvimento Científico e Tecnológico (MCT/CNPQ), Fundação de Amparo à Ciência e Tecnologia do Estado de Pernambuco (FACEPE), and the Coordenação de Aperfeiçoamento de Pessoal de Nível Superior (CAPES).

\section{References}

Azevêdo, W. M., Falcão, E. H. L., \& Petrov, D. V. (2002). First Hyperpolarizability and multiphoton induced fluorescence in different forms of polyaniline. Mol. Cryst. Liq. Cryst., 374, 481-486. http://dx.doi.org/10.1080/713738303

Bartllet, P. N., \& Astier, Y. (2000). Microelectrochemical enzyme transistors. Chem. Comunn., 105-112. Retrieved from http://eprints.soton.ac.uk/id/eprint/18973

Bernard, M. C., Hugot-Le, G. A., Joiret, S., \& Phong, P. V. (2001). Polyaniline films for protection against corrosion. Synth. Met., 119, 283-284.

Blanchard-Desce, M., Alain, V., Bedworth, P. V., Marder, S. R., Fort, A., Runser, C., ... Wortmann, R. (1997a). Large quadratic hyperpolarizabilities with donor-acceptor polyenes exhibiting optimum bond length alternation: correlation between structure and hyperpolarizability. Chem. Eur. J., 3(7), 1091-1104. http://dx.doi.org/10.1002/chem.19970030717

Blanchard-Desce, M., Alain., V., Midrier, L., Wortmann, R., Lebus, S., Glania, C., ... Barzoukas, M. (1997b). Intramolecular charge transfer and enhanced quadratic optical non-linearities in push-pull polyenes. Photochem. Photobiol. A: Chem., 105, 115-121. http://dx.doi.org/10.1016/S1010-6030(96)04547-9

Boudreaux, D. S., Chance, R. R., Wolf, J. F., Shacklette, L. W., Brédas, J. L., Thémans, B., ... Silbey, R. J. (1986). Theoretical-Studies on polyaniline. J. Chem. Phys., 85, 4584-4590. http://dx.doi.org/10.1063/1.451779

Brédas, J. L., Adant, C., Tackx, P., Persoons, A., \& Pierce, B. M. (1994). Third-order nonlinear-optical response in organic materials - theoretical and experimental aspects. Chem. Rev., 94, 243-278. http://dx.doi.org/10.1021/cr00025a008

Brennand, R. A., \& Machado, A. E. de A. (2010). Enhanced first hyperpolarizability of donor acceptor diethynylsilane oligomers. Journal of Computational Methods in Sciences and Engineering, 10, 219-226. Retrieved from http://iospress.metapress.com/content/rv8661 kj31123083/

Burland, D. M., Miller, R. D., \& Walsh, C. A. (1994). Second-order nonlinearity in poled-polymer systems. Chem. Rev., 94, 31-75. http://dx.doi.org/10.1021/cr00025a002

Cao, Y., Smith, P., \& Heeger, A. J. (1992). Counter-ion induced processibility of conducting polyaniline and of conducting polyblends of polyaniline in bulk polymers. Synth. Met., 48, 91-97. http://dx.doi.org/10.1016/0379-6779(92)90053-L

Champagne, B., \& Kirtman, B. (2001). In H. S. Nalwa (Ed.), Handbook of Advanced Electronic and Photonic Materials and Devices, 9, Nonlinear Optical Materials, Academic, San Diego, Chapter 2. 
Chandrasoma, A., Grant, R., Bruce, A. E., \& Bruce, M. R. M. (2012). Electrochemical polymerization of aniline on carbon-aluminum electrodes for energy storage. Journal of Power Sources, 219, 285-29. http://dx.doi.org/10.1016/j.jpowsour.2012.07.028

Cheng, L. T., Tam, W., Stevenson, S. H., Meredith, G. R., Rikken, G., \& Marder, S. R. (1991). Experimental investigations of organic molecular nonlinear optical polarizabilities. 1. Methods and results on benzene and stilbene derivatives. J. Phys. Chem., 95, 10631-10643. http://dx.doi.org/10.1021/j100179a026

Costa, M. B. S., Machado, A. E. de A., \& Pavão, A. C. (2012). Theoretical assessment of the nonlinear optical properties of substituted oligoacenes. Journal of Materials Science, 48, 192-200. http://dx.doi.org/10.1007/s10853-012-6728-0

Costa, M. B. S., Machado, A. E. de A., \& Barros, N. B. (2007). Partial least squares prediction of the hyperpolarizabilities of aniline octamer derivatives. Comp. Lett., 3, 267-276. http://dx.doi.org/10.1163/157404007782913228

Delongchamp, D., \& Hammond, P. T. (2001). Layer-by-Layer Assembly of PEDOT/Polyaniline Electrochromic

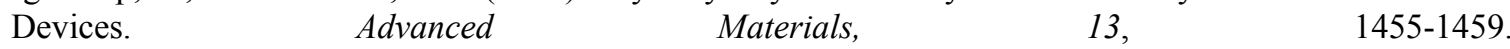
http://dx.doi.org/10.1002/1521-4095(200110)13:19<1455::AID-ADMA1455>3.0.CO;2-7

Deshmukh, V., Kharat, B., \& Chaudhari, A. (2012). Nonlinear optical properties and spectroscopic characterization of aniline in singlet, triplet and quintet state using quantum chemical methods. Computational and Theoretical Chemistry, 980, 115-122. http://dx.doi.org/10.1016/j.comptc.2011.11.036

Dewar, M. J. S., Zoebisch, E. G., Healy, E. F., \& Stewart, J. J. P. (1985). Development and use of quantum mechanical molecular models. 76. AM1: a new general purpose quantum mechanical molecular model. $J$. Am. Chem. Soc., 107, 3902-3909. http://pubs.acs.org/doi/abs/10.1021/ja00299a024

Dykstra, C. E., \& Jasien, P. G. (1984). Derivative Hartree-Fock theory to all orders. Chem. Phys. Lett., 109, 388-393. http://dx.doi.org/10.1016/0009-2614(84)85607-9

Fan, Z. Q., Zhang, Z. H., Qiu, M., \& Tang, G. P. (2011). Rectifying performance and reversible conductance switching of single-polyaniline devices. Physics Letters A, 375, 3314-3318. http://dx.doi.org/10.1016/j.physleta.2011.07.023

Fitrilawati, F., \& Tjia, M. O. (2001). Effects of phenylene ring derivatization of polyaniline on its optical properties. Opt. Mater., 16, 361-367. http://dx.doi.org/10.1016/S0925-3467(00)00047-1

Geniès, E. M., Boyle, A., Lapkowski, M., \& Tsintavis, C. (1990). Polyaniline: A historical survey. Synth. Met., 36, 139-182. http://dx.doi.org/10.1016/0379-6779(90)90050-U

Guo, H., Knobler, C. M., \& Kaner, R. B. (1999). A chiral recognition polymer based on polyaniline. Synth. Met., 101, 44-47. http://dx.doi.org/10.1016/S0379-6779(98)00301-4

Halvorson, C., Cao, Y., Moses, D., \& Heeger, A. J. (1993). Third order nonlinear optical susceptibility of polyaniline. Synth. Met., 55-57, 3941-3944. http://dx.doi.org/10.1016/0379-6779(93)90538-8

Jansen, S. A., Duong, T., Major, A., Wei, Y., \& Sein Jr., L. T. (1999). Evolution of the electronic states of polyaniline: an ab initio analysis of the orbital states of PAni synthons. Synth. Met., 105, 107-113. http://dx.doi.org/10.1016/S0379-6779(99)00083-1

Kanis, D. R., Ratner, M. A., \& Marks, T. J. (1994). Design and construction of molecular assemblies with large second-order optical nonlinearities. Quantum chemical aspects. Chem. Rev., 94, 195-242. http://pubs.acs.org/doi/abs/10.1021/cr00025a007

Karna, S. P., \& Dupuis, M. J. (1991). Frequency dependent nonlinear optical properties of molecules. J. Comp. Chem., 12, 487-504. http://link.aip.org/link/doi/10.1063/1.451255

Kim, Y., Kobayashi, N., Teshima, K., \& Hirohashi, R. (1999). Photorewritable conducting polyaniline image formation with photoinduced electron transfer. Synth. Met., 101, 699-700. http://dx.doi.org/10.1016/S0379-6779(98)01011-X

Ledoux, I., Zyss, J., Jutand, A., \& Amatore, C. (1991). Nonlinear optical properties of asymmetric polyphenyls: Efficiency versus transparency trade-off. Chem. Phys., 150, 117-123. http://dx.doi.org/10.1016/0301-0104(91)90061-W

Libert, J., Cornil, J., dos Santos, D. A., \& Brédas, J. L. (1997). From neutral oligoanilines to polyanilines: a theoretical investigation of the chain-length dependence of the electronic and optical properties. Phys. Rev. B, 
56, 8638-8650. http://link.aps.org/doi/10.1103/PhysRevB.56.8638

MacDiarmid, A. G. (1997). Polyaniline and polypyrrole: Where are we headed? Synth. Met., 84, 27-34. http://dx.doi.org/10.1016/S0379-6779(97)80658-3

Machado, A. E. de A. (2001). Hiperpolarizabilidades semi-empiricas de sistemas orgânicos doador-receptor (Ph.D. Thesis). Universidade Federal de Pernambuco, Brazil.

Machado, A. E. de A., \& da Gama, A. A. S. (2003). Calculations of second hyperpolarizabilities of some polyenic derivatives. J. Molec. Struct. (THEOCHEM), 620, 21-29. http://dx.doi.org/10.1016/S0166-1280(02)00475-X

Machado, A. E. de A., \& da Gama, A. A. S. (2005). Large first hyperpolarizabilities of substituted aniline oligomers. Int. J. Quantum Chem., 103, 625-631. http://dx.doi.org/10.1002/qua.20557

Machado, A. E. de A., De Souza, L. A., Dos Santos, Hélio, F., De Almeida, \& Wagner, B. (2011b). Donor-acceptor diethynylsilane oligomers: a second-order nonlinear optical material. Journal of Polymer Science Part B: Polymer Physics, 49, 1410-1419. http://dx.doi.org/10.1002/polb.22324.

Machado, A. E. de A., Gama, A. A. S., \& Neto, B. B. (2008). Enhanced Optical Nonlinearities in Push-Pull Organic Systems with Polyenic-Mesoionic Ring Mixed Bridges. J. Braz. Chem. Soc., 19, 1381-1387. http://dx.doi.org/10.1590/S0103-50532008000700022

Machado, A. E. de A., Gama, A. A. S., \& Neto, B. B. (2011a). Partial least squares prediction of the first hyperpolarizabilities of donor-acceptor polyenic derivatives. Chemical Physics, 388, 19-22. http://dx.doi.org/10.1016/j.chemphys.2011.07.007

Machado, A. E. de A., Neto, B. B., \& Gama, A. A. S. (2004). PLS Prediction of Hyperpolarizabilities for Donor-bridge-acceptor Organic Systems. Journal of Computational Methods in Sciences and Engineering, 4, 267-275. Retrieved from http://iospress.metapress.com/content/tte77ty91p84crgk/

Machado, A. E. de A., Petrov, D. V., Falcão, E. H. L., da Gama, A. A. S., \& Azevêdo, W. M. (2002). Semiempirical calculations of aniline oligomers hyperpolarisabilities. Chemical Physics Letters, 356, 451-456. http://dx.doi.org/10.1016/S0009-2614(02)00345-7

Maciel, G. S., de Araújo, C. B., Correia, R. R. B., \& de Azevêdo, W. M. (1998). Nonlinear optical response of $\begin{array}{llllll}\text { polyaniline liquid } & \text { Solutions. }\end{array}$ http://dx.doi.org/10.1016/S0030-4018(98)00449-0

Marder, S. R., Torruellas, W. E., Blanchard-Desce, M., Ricci, V., Stegeman, G. I., Gilmour, S., ... Boxer, S. G. (1997). Large molecular third-order optical nonlinearities in polarized carotenoids. Science, 276, 1233-1236. http://dx.doi.org/10.1126/science.276.5316.1233

MOPAC2009. (2008). James J. P. Stewart, Stewart Computational Chemistry, Colorado Springs, CO, USA, Retrieved from http://OpenMOPAC.net

Morley, J. O., Docherty, V. J., \& Pugh, D. (1987). Non-linear optical properties of organic molecules. Part 2. Effect of conjugation length and molecular volume on the calculated hyperpolarisabilities of polyphenyls and polyenes. J. Chem. Soc. Perkin Trans. II, 2, 1351-1355. http://dx.doi.org/10.1039/P29870001351

Moura, G. L. C., Simas, A. M., \& Miller, J. (1996). Mesoionic rings as efficient asymmetric bridges for the design of compounds with large optical nonlinearities. Chemical Physics Letters, 257, 639-646. http://dx.doi.org/10.1016/0009-2614(96)00601-X

Nemzera, L. R., \& Epsteina, A. J. (2010). A polyaniline-based optical biosensing platform using an entrapped oxidoreductase enzyme. Sensors and Actuators B, 150, 376-383. http://dx.doi.org/10.1016/j.snb.2010.06.054

Osaheni, J. A., Jenekhe, S. A., Vanherzeele, H., Meth, J. S., Sun, Y., \& MacDiarmid, A. G. (1992). Nonlinear optical properties of polyanilines and derivatives. J. Phys. Chem., 96, 2830-2836. http://pubs.acs.org/doi/abs/10.1021/j100186a010

Parente, A. H., Marques, E. T. A., Azevêdo, W. M., Diniz, F. B., Melo, E. H. M., \& Filho, J. L. L. (1992). Glucose biosensor using glucose oxidase immobilized in polyaniline. Appl. Biochem. Biotech., 37, 267-273. http://dx.doi.org/10.1007/BF02788878

Romaniello, P., \& Francesco, L. (2004). Effects of fluorine atoms on the optical nonlinear response of stilbene derivatives. Journal of Fluorine Chemistry, 125, 145-149. http://dx.doi.org/10.1016/j.jfluchem.2003.10.002

Sajeev, U. S., Nambuthiri, V. V., Salah, A., Nampoori, V. P. N., \& Anantharaman, M. R. (2010). Studies on the nonlinear optical properties of rf plasma polymerized aniline thin films by open aperture z-scan technique. 
Synthetic Metals, 160, 1704-1707. http://dx.doi.org/10.1016/j.synthmet.2010.06.004

Santos, M. C., \& Brédas, J. L. (1989). Nonlinear excitations in pernigraniline, the oxidized form of polyaniline. Phys. Rev. Lett., 62, 2499-2502. http://dx.doi.org/10.1103/PhysRevLett.62.2499.

Sein Jr., L. T., Wei, Y., Duong, T., Kemmerer, M. D., \& Jansen, S. A. (1999). Anomalous failure of configuration interaction - singles (cis) method in the computation of the electronic states of $N, N^{\prime}$-bis (4'-aminophenyl)-1,4-quinonediimine. Int. J. Quantum Chem., 75, 623-629.

Sein Jr., L. T., Wei, Y., \& Jansen, S. A. (2000a). Trimeric anilines as both donors and acceptors: an experimental and computational study. Synth. Met., 108, 101-106. http://dx.doi.org/10.1016/S0379-6779(99)00163-0

Sein Jr., L. T., Wei, Y., \& Jansen, S. A. (2000b). Halogen-capped aniline trimers: away from the polyaniline paradigm by isosteric replacement of amino groups: a theoretical study. J. Phys. Chem. A, 104, 11371-11374. http://pubs.acs.org/doi/abs/10.1021/jp001404g

Stewart, J. J. P. (1996). Application of localized molecular orbitals to the solution of semiempirical self-consistent field equations. International Journal of Quantum Chemistry, 58, 133-146.

Vaschetto, M. E., \& Retamal, B. A. (1997). Substituents effect on the electronic properties of aniline and oligoanilines. J. Phys. Chem. A, 101, 6945-6950. http://pubs.acs.org/doi/abs/10.1021/jp970029y

Vaschetto, M. E., Retamal, B. A., \& Monkman, A. P. (1999). Density functional studies of aniline and substituted anilines. J. Molec. Struct. (THEOCHEM), 468, 209-221. http://dx.doi.org/10.1016/S0166-1280(98)00624-1

Vivier, V., Cachet-Vivier, C., Cha, C. S., Nedelec, J. Y., \& Yu, L. T. (2000). Cavity microelectrode for studying battery materials: application to polyaniline powder. Electrochem. Commun., 2, 180-185. http://dx.doi.org/10.1016/S1388-2481(00)00004-7

Yan, L. K., Jin, M. S., Zhuang, J., Liu, C. G., Su, Z. M., \& Sun, C. C. (2008). Theoretical study on the considerable second-order nonlinear optical properties of naphthylimido-substituted hexamolybdates. Journal of Physical Chemistry A, 112, 9919-9923. http://dx.doi.org/10.1021/jp804342h

Zhao, L., Zhao, L., Xu, Y., Qiu, T., Zhi, L., \& Shi, G. (2009). Polyaniline electrochromic devices with transparent graphene electrodes. Electrochimica Acta, 55, 491-497. http://dx.doi.org/10.1016/j.electacta.2009.08.063 